Shepherd, M., M. Cross, M. J. Dieters and R. Henry (2003): Genetic maps for Pinus elliottii var elliottii and $P$. caribaea var. hondurensis using AFLP and mierosatellite markers. Theoretical and Applied Genetics 106: 1409-1419. doi: 10.1007/s00122-002-1185-9

Shepherd, M., T. Maguire, M. Dieters and R. Henry (2002): Transpecific microsatellites for hard pines. Theoretical and Applied Genetics 104: 819-827. doi: 10.1007/s00122-001-0794-z

STAM, P. (1993): Construction of integrated genetic linkage maps by means by a new computer package: JoinMap. The Plant Journal 3: 739-744.

Temesgen, B., G. R. Brown, D. E. Harry, C. S. Kinlaw, M. M. Sewell and D. B. Neale (2001): Genetic mapping of expressed sequence tag polymorphism (ESTP) markers in loblolly pine (Pinus taeda L.). Theoretical and Applied Genetics 102: 664-675. doi: 10.1007/ s001220051695

Van OoIJEN, J.W. (2006): Joinmap 4, Software for the calculation of genetic linkage maps in experimental populations. Kyazma B.V, Wageningen, Netherlands.

VOORRIPS, R. E. (2002): MapChart: Software for the graphical presentation of linkage maps and QTLs. Journal of Heredity 93: 77-78. doi:10.1093/jhered/93.1.77
YIN, T. M., M. R. HuANG, M. X. WANG, L. H. ZHU and W. X. ZHAI (1997): Construction of molecular linkage map in masson pine using RAPD markers and megagametophytes from a single tree (Chinese). Acta Botanica Sinica 39: 607-612.

Yin, T. M., X. R. WANG, B. ANDERsson and E. LeRCETEAUKÖHLER (2003): Nearly complete genetic maps of Pinus sylvestris L. (Scots pine) constructed by AFLP marker analysis in a full-sib family. Theoretical and Applied Genetics 106: 1075-1083. doi: 10.1007/s00122-0031194-3

Yin, T. M., S. P. Difazio, L. E. Gunter, D. RiemenSCHNEIDER and G. A. TUSKAN (2004): Large-scale heterospecific segregation distortion in Populus revealed by a dense genetic map. Theoretical and Applied Genetics 109: 451-463. doi: 10.1007/s00122-004-1653-5

Zhang, B., L. Zhang, Q. Zhuge, M. X. Wang and M. R. HUANG (2004): A rapid and simple method of total DNA extraction from tree (in Chinese). Journal of Nanjing Forest University 28: 13-16.

Zheng, X., B. Chen, Q. TANG and L. Wei (1997): The construction of genetic linkage mapping for individual of Pinus massoniana by RAPDs marker (Chinese). Journal of Basic Sciencie and Engineering 5: 181-186.

\title{
Performance of Eucalyptus Clones in Auto and Allocompetition
}

\author{
By G. S. Martins ${ }^{1)}$, G. P. L. Moura ${ }^{2)}$, M. A. P. Ramalho ${ }^{3)}$ and F. M. A. Gonçalves ${ }^{3)}$
}

(Received $27^{\text {th }}$ February 2013)

\begin{abstract}
This study was performed to estimate the abilities of eucalyptus clones to exercise as well as to tolerate competition and to compare their behaviors under auto- or allocompetition. Six commercial clones, belonging to PLANTAR S/A enterprise were evaluated for breast height circumference (BHC), total height (TH) and volume (VOL). At three locations of Minas Gerais, Brazil (two in Curvelo and one in Felixlândia) the clones were planted in two spaces. At 36 months of age each clone was evaluated for exercising and toleration competition amongst each other. The design for each experiment was similar to that of the nine-hole system; the center clone being under competition and the eight surrounding the

\footnotetext{
1) Corresponding author: Gustavo Salgado Martins. Plantar S/A - Planejamento, técnica e administração de reflorestamentos (Planning, techniques and management of reforestation). Faz. Buenos Aires II, Rod. 135, Km 636 - Zona rural. CEP 35790-000/Curvelo - MG, Brazil.

Phone: +55 38 37291000, Fax: +55 3837291009 .

E-Mail: gustavosalgadomartins@gmail.com

2) Plantar S/A - Planejamento, técnica e administração de reflorestamentos. Av. Raja Gabaglia, 1.380 - Gutierrez. CEP 30440452/Belo Horizonte - MG, Brazil.

3) Departamento de Biologia, Universidade Federal de Lavras,
} Caixa Postal 3037, CEP 37200-000/Lavras, MG, Brazil.
\end{abstract}

center clone exercising competition. Each clone under competition was repeated eight times; therefore, for each spacing and location, six contiguous experiments were conducted. From the mean values; the parameters of ability to exercise competition $\left(c_{i}\right)$, ability to tolerate competition $\left(\mathrm{t}_{\mathrm{j}}\right)$, the specific competitive ability $\left(\mathrm{s}_{\mathrm{ij}}\right)$ and the performance per se of the clones $\left(\mathrm{a}_{\mathrm{j}}\right)$ were estimated using a model similar to that of diallel crosses. The clones differed as to their $c_{i}, t_{j}$ and $a_{j}$. No one clone exhibited high and positive $c_{i}$ and $t_{j}$. Regardless of location, spacing, or clone, the performance of autocompetition is similar to that of allocompetition. This indicates that a mixture of clones, if advantageous from the management or industrial point of view, may be performed without harm to the volume of wood produced.

Key words: Eucalyptus, competition, mixture, clone, autocompetition, allocompetition, uniformity.

\section{Introduction}

With the refinement of clone propagation techniques and its application to produce eucalyptus saplings at a commercial scale, it has been possible to establish uniform forests that are now widely used in production of raw material for industrial use. Companies generally have a few clones available which are planted in blocks 
of monoclonal plantations, usually in extensive areas. A plausible question is whether it would be advantageous, or not, to adopt a mixture of clones? In doing this each block would be composed of a mixture of clones, breaking up the genetic uniformity present in the current monoclonal blocks.

This mixture could offer advantages such as greater stability in the face of environmental variations, specifically in soil type and climatic conditions. The expectation is that if one clone does not show desirable performances in one environment the other clones may be able to compensate the deficiency; thus, on average, the behavior of the mixture would be more advantageous (Helland; Holland, 2001; BRuzi et al., 2007; BotelHo et al., 2011). An additional significant argument is that each clone may differ in regards to pest and disease resistance. In using genetic variability, the vulnerability of outbreaks and epidemics due to genetic uniformity should be reduced (NATIONAL ACADEMY OF SCIENCES NAS, 1972).

Although these advantages may be easily seen, not many research reports involving mixture of eucalyptus clones have been found, although this type of information has already been obtained for other species (SILVA et al., 2007; BotELHo et al., 2011). In these works, the focus was only in the context of multilines aimed at obtaining bean cultivars with longer lasting genetic resistance to pathogens.

While considering the adoption of a mixture of clones there are some aspects which should be emphasized, mainly those relating to the competition that exists amongst trees which compose a forest. Upon altering the uniformity of genetic composition, the competition which exists among the plants is also altered. In the monoclonal blocks the competition is described as autocompetition, and when a mixture of clones is adopted the standard of competition is called allocompetition. Thus, the advantage of using a mixture depends on the adequate choice of clones to be used, which is essential for successful growth. The idea is to associate clones in a mixed manner that presents the least possible competition among themselves. Therefore, the objectives of this study were to estimate the parameters associated with the clonal abilities to exercise as well as to tolerate competition. This will permit prediction of success in adopting a mixture of clones.

\section{Materials and Methods}

Experiments to study competition between clones were set up in farms belonging to the forest enterprise PLANTAR S/A at three locations. Two of the farms are in the municipality of Curvelo (Lagoa do Capim and Meleiros), MG, Brazil, at 700 meters altitude, $18^{\circ} 50^{\prime}$ latitude South and $44^{\circ} 35^{\prime}$ longitude West, with a mean annual rainfall of $1380 \mathrm{~mm}$. The third farm is in the municipality of Felixlândia (Buritis), MG, at 617 meters altitude, $18^{\circ} 39^{\prime}$ latitude South and $45^{\circ} 2^{\prime}$ longitude West, with a mean annual precipitation of $1291 \mathrm{~mm}$. The experiments were set up in two different time periods, the first being in Lagoa do Capim in August 2007, and the second in Meleiros and Buritis in March 2008.

Based on performance and current use, six commercial eucalyptus clones (A, B, C, D, E and F) were chosen and evaluated. Clone $\mathrm{C}$ is an $E$. urophylla $\times$ E. grandis hybrid. The others are clones obtained from Eucalyptus urophylla populations. The experiments were planted in two spacings $(3.0 \times 1.5 \mathrm{~m}$ and $3.0 \times 3.0 \mathrm{~m})$.

In all locations, each clone was evaluated for its ability to both exercise and tolerate competition in the two planting spaces using one plant per plot. The arrangement adopted in each experiment is presented in Figure 1. Letter A identifies clone A exercising competition and surrounded by other clones identified by the letters A, B, $\mathrm{C}, \mathrm{D}, \mathrm{E}$ and $\mathrm{F}$. The clone undergoing competition is repeated eight times. The same experiment was adopted for clones B, C, D, E and F each exercising competition. Thus, at each spacing, six contiguous experiments were set up, such that at each location, 12 experiments were conducted, for a total of 36 experiments.

\begin{tabular}{|c|c|}
\hline 1 & AAAAAAAAAAAAAAAAAAAAAAAAAAAAAAAAAAA \\
\hline 2 & AAA AAA AAAAAAAAAAAAAAAAAAAAAAAAAAAAAAAAA \\
\hline 3 & 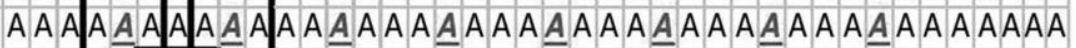 \\
\hline 4 & 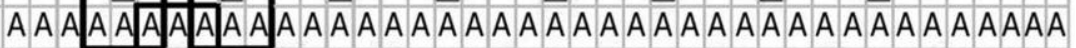 \\
\hline 5 & $A A A A A A \underline{B} A A \underline{B} A A A \underline{B} A A A \underline{B} A A \underline{B} A A A \underline{B} A A A \underline{B} A A A \underline{B} A A A A$ \\
\hline 6 & 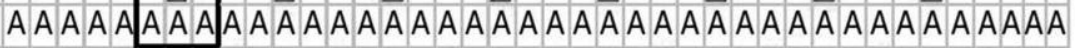 \\
\hline 7 & 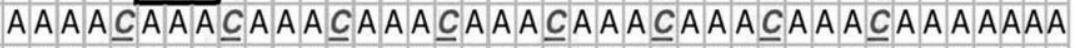 \\
\hline 8 & A $A A A \bar{A} A A A \bar{A} A A A \bar{A} A A A \bar{A} A A A \bar{A} A A A \bar{A} A A A \bar{A} A A A \bar{A} A A A A A A A$ \\
\hline 9 & 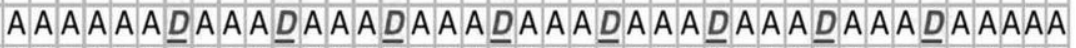 \\
\hline 10 & 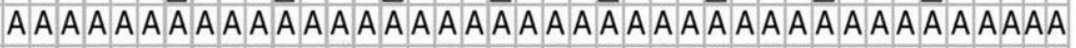 \\
\hline 11 & 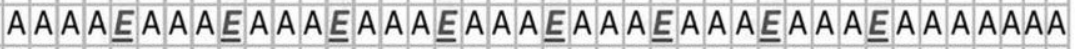 \\
\hline 12 & 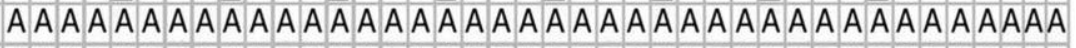 \\
\hline 13 & A A A A A A $\underline{F} A A A \underline{F} A A A \underline{F} A A A \underline{F} A A A \underline{F} A A \underline{F} A A A \underline{F} A A A \underline{F} A A A A$ \\
\hline 14 & AAAAAA $\bar{A} A A A \bar{A} A A A \bar{A} A A A \bar{A} A A A \bar{A} A A A \bar{A} A A A \bar{A} A A A \bar{A} A A A A A$ \\
\hline 15 & $A A A A A A A A A A A A A A A A A A A A A A A A A A A A A A A A A A A A A A A A$ \\
\hline
\end{tabular}

Figure 1. - Arrangement of one of the twelve experiments of each environment involved in the study of competition between clones. The letter A represents the clone exercising competition. The underlined letters correspond to the clones undergoing competition, and each letter corresponds to a different clone. 
For preparation of the area, subsoiling was performed at a depth of $45 \mathrm{~cm}$ with the application of $400 \mathrm{~kg}$ of phosphate and $150 \mathrm{~kg}$ of $\mathrm{KCl}+1 \%$ of boron per hectare. In the topdressing fertilization, $100 \mathrm{~g}$ of 6-30-6 fertilizer with $1 \%$ boron and zinc per plant was used. The other crop treatments (replanting, weeding, irrigation and others) were performed when necessary, according to the recommendations provided by the company for commercial planting.

In all the experiments at 36 months of age data on breast height circumference (BHC), in centimeters, and total height (TH), in meters, were collected on the plants situated in the center of the nine holes. To obtain individual volume (VOL) data, volumetric equations were used that are routinely used by the company, adjusted for age and expressed in cubic decimeters. Initially, an analysis of variance between and within each type was performed (STEEL et al., 1997), per experiment (clone exercising competition), using the following model:

$$
\mathrm{Y}_{j q}=\mu+\mathrm{t}_{\mathrm{j}}+\mathrm{e}_{j q}
$$

(Model 1)

Where $\mathrm{Y}_{j q}$ : observation in reference to clone $\mathrm{j}$ under competition, in replication $\mathrm{q} ; \mu$ : general mean value of the experiment; $t_{j}$ : effect of clone $j$ under competition, $\mathrm{j}=1,2, \ldots, 6 ; \mathrm{e}_{j q}$ : experimental error associated with observation $\mathrm{Y}_{j q}$, with $\mathrm{e}_{j q} \cap \mathrm{N}\left(0, \sigma^{2}\right)$, with $\mathrm{q}$ being the number of replications $(q=1,2, \ldots, 8)$.

Analysis of variance was carried out involving all the experiments at a given spacing and location, using the following model:

$$
\mathrm{Y}_{i j q}=\mu+\mathrm{a}_{i}+\mathrm{t}_{j}+(\mathrm{at})_{i j}+\bar{e}_{i j q}
$$

(Model 2)

Where $\mathrm{Y}_{i j q}$ : observation in reference to the competition exercised by clone $\mathrm{i}$ (experiment), under clone $\mathrm{j}$ in replication $\mathrm{q} ; \mu$ : general mean value of the experiment; $\mathrm{a}_{i}$ : effect of clone $\mathrm{i}$ exercising competition (experiment), $\mathrm{i}=1,2, \ldots, 6 ; \mathrm{t}_{j}$ : effect of clone $\mathrm{j}$ under competition, $\mathrm{j}=1$, $2, \ldots, 6$; (at) $)_{i j}$ : effect of interaction between clone $i$ which exercises competition and clone $\mathrm{j}$ under competition; $\bar{e}_{i j q}$ : mean experimental error associated with observation $\mathrm{Y}_{i j q}$, with $\bar{e}_{i j q} \cap \mathrm{N}\left(0, \sigma^{2}\right)$.

In a joint analysis, analysis of variance was performed involving all the locations and spacings according to the following model:

$$
\begin{aligned}
\mathrm{Y}_{i j w u q}= & \mu+\mathrm{a}_{i}+\mathrm{t}_{j}+(\mathrm{at})_{i j}+\mathrm{s}_{w}+(\mathrm{as})_{i w}+(\mathrm{ts})_{j w}+(\mathrm{ats})_{i j w} \\
& +\mathrm{l}_{u}+(\mathrm{al})_{i u}+(\mathrm{tl})_{j u}+(\mathrm{atl})_{i j u}+(\mathrm{sl})_{w u}+(\mathrm{asl})_{i w u} \\
& +(\mathrm{tsl})_{j w u}+(\mathrm{atsl})_{i j w u}+\bar{e}_{i j w u q} \quad \text { Model }
\end{aligned}
$$

Where: $\mathrm{Y}_{i j w u q}$ : observation in reference to competition exercised by clone $\mathrm{i}$ (experiment), under clone $\mathrm{j}$, at spacing $\mathrm{w}$, in location $\mathrm{u}$ and in replication $\mathrm{q} ; \mu$ : general mean value of the experiment; $a_{i}$ : effect of clone $i$ exercising competition (experiment), $\mathrm{i}=1,2, \ldots, 6$; $\mathrm{t}_{j}$ : effect of clone $\mathrm{j}$ under competition, $\mathrm{j}=1,2, \ldots, 6$; (at) ${ }_{i j}$ : effect of interaction between clone $\mathrm{i}$ which exercises competition and clone $\mathrm{j}$ under competition; $\mathrm{s}_{w}$ : effect of spacing $\mathrm{w}, \mathrm{w}=1$, 2 ; (as) $)_{i w}$ : effect of interaction between clone i exercising competition and the spacing $\mathrm{w}$; $(\mathrm{ts})_{j w}$ : effect of interaction between clone $\mathrm{j}$ under competition and the spacing $\mathrm{w}$; (ats) $)_{i j w}$ : effect of the interaction between clone i exercising competition, clone $\mathrm{j}$ under competition and spac- ing $\mathrm{w} ; \mathrm{l}_{u}$ : effect of location $\mathrm{u}, \mathrm{u}=1,2,3$; $(\mathrm{al})_{i u}$ : effect of interaction between clone i exercising competition and location $\mathrm{u}$; $(\mathrm{tl})_{j u}$ : effect of interaction between clone $\mathrm{j}$ under competition and location $\mathrm{u}$; (atl) $)_{i j u}$ : effect of interaction between clone $\mathrm{i}$ exercising competition, clone $\mathrm{j}$ under competition and location $\mathrm{u} ;(\mathrm{sl})_{w u}$ : effect of interaction between spacing $\mathrm{w}$ and the location $\mathrm{u}$; (asl) ${ }_{i w u}$ : effect of interaction between clone i exercising competition, spacing $\mathrm{w}$ and location $\mathrm{u}$; $(\mathrm{tsl})_{j w u}$ : effect of interaction between clone $\mathrm{j}$ under competition, spacing $\mathrm{w}$ and location $\mathrm{u}$; (atsl) ${ }_{i j w u}$ : effect of interaction between clone $\mathrm{i}$ exercising competition, clone $\mathrm{j}$ under competition, spacing $\mathrm{w}$ and the location $\mathrm{u} ; \bar{e}_{i j w u q}$ : mean experimental error associated with observation $\mathrm{Y}_{i j w u q}$, with $\bar{e}_{i j w u q} \cap \mathrm{N}\left(0, \sigma^{2}\right)$.

To verify whether or not the clones differ in their abilities to exercise and tolerate competition, a Scheffé test was performed to test the significance between the contrasts of the mean values of each clone exercising and tolerating competition (PIMENTEL-GoMES, 2009).

With the mean data, the competition parameters were estimated using modeling similar to partial diallel analysis for hybrid combinations (FEDERER et al., 1982; Silva et al.,, 2007) following the model:

$$
\overline{\mathrm{Y}}_{\mathrm{ij}}=\mu+\mathrm{c}_{\mathrm{i}}+\mathrm{z}_{\mathrm{j}}+\mathrm{s}_{\mathrm{ij}}+\mathrm{e}_{\mathrm{ij}}
$$

Where $\overline{\mathrm{Y}}_{\mathrm{ij}}$ : mean value of clone $\mathrm{j}$ undergoing competition from clone $i ; \mu$ : general mean value of the experiment; $c_{i}$ : ability to exercise competition of clone $i ; z_{j}$ : tolerance to competition from clone $\mathrm{j}$, whose component involves the per se effect of the clone under competition $\left(a_{j}\right)$ and the effect of tolerance to competition strictly speaking $\left(t_{j}\right)$; in other words, $z_{j}=a_{j}+t_{j} ; s_{i j}$ : specific competitive ability of the pair of clones $i$ and $j ; e_{i j}$ :

Table 1. - Joint analysis of variance (Model 3) for the volume (VOL) variable, expressed in cubic decimeters $\left(\mathrm{dm}^{3}\right)$.

\begin{tabular}{clrl}
\hline \multirow{2}{*}{ Source of variation } & \multicolumn{3}{c}{ VOL } \\
\cline { 2 - 4 } & DF & \multicolumn{1}{c}{ MS } & p-value \\
\hline Locations (L) & 2 & 55877.8 & $<.0001$ \\
Spacings (S) & 1 & 596435.5 & $<.0001$ \\
L x S & 2 & 1427.0 & 0.0113 \\
Treatments (T) & 35 & 7105.7 & $<.0001$ \\
GEC $^{1 /}$ & 5 & 4159.1 & $<.0001$ \\
GTC ${ }^{1 /}$ & 5 & 43032.0 & $<.0001$ \\
SCA ${ }^{1 /}$ & 25 & 506.5 & 0.0316 \\
L x T & 70 & 1471.7 & $<.0001$ \\
L x GEC & 10 & 4796.1 & $<.0001$ \\
L x GTC & 10 & 2050.4 & $<.0001$ \\
L x SCA & 50 & 688.6 & $<.0001$ \\
S x T & 35 & 1402.5 & $<.0001$ \\
S x GEC & 5 & 3399.7 & $<.0001$ \\
S x GTC & 5 & 3596.8 & $<.0001$ \\
S x SCA & 25 & 573.7 & 0.0087 \\
L x S x T & 70 & 1381.3 & $<.0001$ \\
L x S x GEC & 10 & 4964.7 & $<.0001$ \\
L x S x GTC & 10 & 1322.8 & $<.0001$ \\
L x S x SCA & 50 & 676.6 & $<.0001$ \\
Error & 1497 & 317.5 & \\
\hline Mean & & 80.48 & \\
\hline
\end{tabular}

${ }^{1 /}$ GEC - General ability to exercise competition; GTC - general ability to tolerate competition and SCA - specific competitive ability. 
Table 2. - Mean values of the clones in autocompetition and allocompetition for volume and mean annual increment ( $\mathrm{m}^{3} /$ ha/year) in the mean value of the locations for spacings, and mean values of the clones for volume in the mean value of the spacings for locations. Data obtained at 36 months of age.

\begin{tabular}{|c|c|c|c|c|c|c|c|c|c|c|c|c|}
\hline \multirow[b]{3}{*}{ Clones } & \multicolumn{4}{|c|}{ Spacings } & \multicolumn{6}{|c|}{ Locations } & \multirow{2}{*}{\multicolumn{2}{|c|}{ Mean }} \\
\hline & \multicolumn{2}{|c|}{$3.0 \times 1.5 \mathrm{~m}$} & \multicolumn{2}{|c|}{$3.0 \times 3.0 \mathrm{~m}$} & \multicolumn{2}{|c|}{ Meleiros } & \multicolumn{2}{|c|}{ Buritis } & \multicolumn{2}{|c|}{ Lagoa do Capim } & & \\
\hline & Auto MAI & Alo MAI & Auto MAI & Alo MAI & Auto & Alo & Auto & Alo & Auto & Alo & Auto & Alo \\
\hline A & 58.243 .1 & 37.928 .1 & 80.229 .7 & 83.931 .1 & 60.1 & 65.3 & 58 & 52.1 & 89.5 & 65.9 & 69.2 & 61.1 \\
\hline B & 56.141 .6 & 69.051 .1 & 103.238 .2 & 97.236 .0 & 68.3 & 80.7 & 70 & 71.9 & 100.7 & 97 & 79.7 & 83.2 \\
\hline $\mathrm{C}$ & 54.640 .4 & 53.939 .9 & 88.732 .9 & 89.933 .3 & 65.6 & 72.6 & 73.5 & 61.4 & 76.3 & 81.7 & 71.7 & 72.0 \\
\hline D & 65.648 .6 & 68.150 .4 & 91.133 .7 & 95.735 .4 & 70.3 & 79.1 & 72.6 & 73.2 & 92.2 & 93 & 78.4 & 81.8 \\
\hline $\mathrm{E}$ & 72.753 .9 & 75.555 .9 & 123.745 .8 & 117.943 .7 & 95.8 & 82.7 & 92.7 & 96.7 & 106.0 & 110.6 & 98.2 & 96.7 \\
\hline $\mathrm{F}$ & 65.748 .7 & 67.750 .1 & 103.438 .3 & 112.641 .7 & 80.1 & 85.5 & 70.5 & 85.4 & 103.4 & 99.6 & 84.6 & 90.2 \\
\hline Média & 62.146 .0 & 62.045 .9 & 98.436 .4 & 99.536 .9 & 73.4 & 77.7 & 72.9 & 73.4 & 94.7 & 91.3 & 80.3 & 80.8 \\
\hline
\end{tabular}

experimental error associated with observation $\overline{\mathrm{Y}}_{\mathrm{ij}}$, with $\mathrm{e}_{\mathrm{ij}} \cap \mathrm{N}\left(0, \sigma^{2}\right)$.

To estimate $a_{j}$, it was considered that $i=j$, in other words, the clone exercising competition on itself (autocompetition). Thus, $\mathrm{a}_{\mathrm{j}}=\overline{\mathrm{Y}}_{\mathrm{jj}}-\overline{\mathrm{Y}}$.. and $\mathrm{t}_{\mathrm{j}}=\mathrm{z}_{\mathrm{j}}-\mathrm{a}_{\mathrm{j}}$, where $\overline{\mathrm{Y}}_{\mathrm{jj}}$ : mean value of clone $\mathrm{j}$ in autocompetition; $\overline{\mathrm{Y}}_{\mathrm{j}}$..: general mean value of all clones in autocompetition.

The Ordinary Least Squares method was used for estimating the parameters of the model. The significances of the ci and sij parameters were obtained by a t-test. All statistical analyses were performed using the software R (R Development Core Team, 2010).

\section{Results}

Most of the experiments showed a significant effect between the clones $(P \leq 0.05)$ for BHC, TH and VOL. Of the 36 experiments regarding volume, the source of vari-

Table 3. - Contrasts between the mean performance of each clone exercising and tolerating competition, and their significances relative to the minimum significant difference calculated by the Scheffé test at the level of $5 \%$ probability, at 36 months of age.

\begin{tabular}{cccc}
\hline Clone & Yi. & Y.i & Yi. - Y.i \\
\hline A & 91.39 & 61.08 & $*$ \\
B & 79.96 & 83.26 & n.s \\
C & 84.02 & 71.89 & $*$ \\
D & 77.74 & 81.84 & n.s \\
E & 76.15 & 96.69 & $*$ \\
F & 75.88 & 90.38 & $*$ \\
\hline
\end{tabular}

* - significant; n.s - not significant.

Table 4. - Competition parameters (Model 4) for the volume (VOL) variable in the mean value of the locations by spacing, at 36 months of age.

\begin{tabular}{|c|c|c|c|c|c|c|}
\hline \multirow[b]{2}{*}{ Clones } & \multicolumn{3}{|c|}{$3.0 \times 1.5 \mathrm{~m}$} & \multicolumn{3}{|c|}{$3.0 \times 3.0 \mathrm{~m}$} \\
\hline & $\mathrm{c}_{\mathrm{i}}$ & $\mathrm{a}_{\mathrm{j}}$ & $t_{j}$ & $\mathrm{c}_{\mathrm{i}}$ & $\mathrm{a}_{\mathrm{j}}$ & $t_{j}$ \\
\hline $\mathrm{A}$ & $10.36^{*}$ & -3.93 & -16.84 & $3.67^{*}$ & -18.21 & 2.17 \\
\hline B & $-5.01^{*}$ & -6.07 & 10.89 & $3.05^{*}$ & 4.84 & -5.95 \\
\hline $\mathrm{C}$ & 1.04 & -7.56 & -0.43 & 1.53 & -9.66 & 0.01 \\
\hline D & -1.99 & 3.44 & 2.20 & $-3.72^{*}$ & -7.28 & 2.85 \\
\hline $\mathrm{E}$ & $-4.90^{*}$ & 10.58 & 2.42 & $2.84^{*}$ & 25.26 & -5.74 \\
\hline $\mathrm{F}$ & 0.51 & 3.55 & 1.76 & $-7.36^{*}$ & 5.04 & 6.67 \\
\hline
\end{tabular}

* Estimate differs from 0 by the t-test at $5 \%$ probability. ation between clones was not significant in four experiments $(P \leq 0.05$; data not presented). In the joint analysis of variance, the results were very similar for the variables $\mathrm{BHC}, \mathrm{TH}$ and VOL. As $\mathrm{BHC}$ and $\mathrm{TH}$ show high correlation with wood volume, special attention will be directed to volume (Table 1).

From the mean values of the clones in auto and allocompetition throughout the different spacings and locations, it may be observed that there was an increase of approximately $23 \%$ in volume when the mean value obtained in Lagoa do Capim was compared with Buritis. With an increase in spacing between the plants from $3.0 \times 1.5 \mathrm{~m}$ to $3.0 \times 3.0 \mathrm{~m}$, there was an increase of approximately $60 \%$ in individual volume; however, there was a decrease of approximately $20 \%$ in mean annual increment (Table 2).

From the behavior estimates of the clones in each location and spacing, it may be observed that the difference between the mean performance of the clones in autocompetition and allocompetition was very similar. The most expressive difference within the locations was in Meleiros, showing mean performance of the clones in allocompetition $\left(77.7 \mathrm{dm}^{3}\right) 5.85 \%$ greater than autocompetition $\left(73.4 \mathrm{dm}^{3}\right.$ ) (Table 2). Considering the mean data of locations and spacings, there was practically no difference between the performance in autocompetition $\left(80.3 \mathrm{dm}^{3}\right)$ and allocompetition $\left(80.8 \mathrm{dm}^{3}\right)$. Only clones A and $\mathrm{E}$ showed autocompetition performance slightly greater than allocompetition (Table 2).

To compare mean performance of each clone exercising and tolerating competition, the Scheffé test was performed (Table 3). It was observed that clones B and D

Table 5. - Competition parameters (Model 4) for the volume (VOL) variable in the mean value of the spacings by location, at 36 months of age.

\begin{tabular}{|c|c|c|c|c|c|c|c|c|c|}
\hline \multirow[b]{2}{*}{ Clones } & \multicolumn{3}{|c|}{ Meleiros } & \multicolumn{3}{|c|}{ Buritis } & \multicolumn{3}{|c|}{ Lagoa do Capim } \\
\hline & $\mathrm{c}_{\mathrm{i}}$ & $a_{j}$ & $t_{j}$ & $\mathrm{c}_{\mathrm{i}}$ & $a_{j}$ & $\mathrm{t}_{\mathrm{j}}$ & $\mathrm{c}_{\mathrm{i}}$ & $a_{j}$ & $t_{j}$ \\
\hline A & 0.65 & -13.28 & 0.78 & $8.10^{*}$ & -14.85 & -5.44 & $12.04 *$ & -5.19 & -16.84 \\
\hline B & $-6.99 *$ & -5.10 & 6.77 & 2.79 & -2.89 & 1.13 & 1.54 & 6.02 & -0.30 \\
\hline $\mathrm{C}$ & -0.44 & -7.76 & 2.28 & $4.97 *$ & 0.62 & -10.58 & -0.75 & -18.41 & 7.31 \\
\hline $\mathrm{D}$ & $-6.07 *$ & -3.07 & 3.78 & 1.94 & -0.32 & 0.08 & $-4.49 *$ & -2.48 & 3.48 \\
\hline $\mathrm{E}$ & $11.84^{*}$ & 22.44 & -14.47 & $-7.55 *$ & 19.86 & 2.80 & $-7.32 *$ & 11.35 & 6.67 \\
\hline F & 1.00 & 6.76 & 0.86 & $-10.25 *$ & -2.40 & 12.00 & -1.02 & 8.71 & -0.33 \\
\hline
\end{tabular}

* Estimate differs from 0 by the t-test at $5 \%$ probability. 
Table 6. - Estimates of the Spearman classifying correlations between the clones in each spacing and location, at 36 months of age.

\begin{tabular}{ccccc}
\hline Spacing & Locations & $\mathrm{c}_{\mathrm{i}}$ & $\mathrm{a}_{\mathrm{j}}$ & $\mathrm{t}_{\mathrm{j}}$ \\
\hline \multirow{3}{*}{$3.0 \times 1.5 \mathrm{~m}$} & Meleiros / Buritis & 0.20 & -0.31 & 0.03 \\
& Meleiros / Lagoa do Capim & 0.94 & 0.77 & 0.94 \\
& Buritis / Lagoa do Capim & 0.27 & -0.03 & 0.14 \\
\hline \multirow{2}{*}{$3.0 \times 3.0 \mathrm{~m}$} & Meleiros / Buritis & -0.75 & 0.89 & 0.20 \\
& Meleiros / Lagoa do Capim & -0.29 & 0.54 & -0.77 \\
& Buritis / Lagoa do Capim & -0.09 & 0.66 & -0.31 \\
\hline Location & Spacings & $\mathrm{c}_{\mathrm{i}}$ & $\mathrm{a}_{\mathrm{j}}$ & $\mathrm{t}_{\mathrm{j}}$ \\
\hline Meleiros & $1,5 / 3,0$ & 0.23 & 0.26 & -0.71 \\
Buritis & $1,5 / 3,0$ & 0.20 & -0.09 & -0.37 \\
Lagoa do Capim & $1,5 / 3,0$ & 0.21 & 0.49 & 0.26 \\
\hline
\end{tabular}

Table 7. - Estimates of ability to exercise $\left(\mathrm{c}_{\mathrm{i}}\right)$, effect per se $\left(\mathrm{a}_{\mathrm{j}}\right)$, and tolerate $\left(t_{j}\right)$ competition (Model 4) for the volume in the mean value of the spacings and locations, at 36 months of age.

\begin{tabular}{ccrr}
\hline Clones & $\mathrm{c}_{\mathrm{i}}$ & \multicolumn{1}{c}{$\mathrm{a}_{\mathrm{j}}$} & \multicolumn{1}{c}{$\mathrm{t}_{\mathrm{j}}$} \\
\hline $\mathrm{A}$ & $6.93^{*}$ & -11.14 & -7.20 \\
$\mathrm{~B}$ & -0.86 & -0.68 & 2.58 \\
$\mathrm{C}$ & 1.19 & -8.68 & -0.24 \\
$\mathrm{D}$ & $-2.93^{*}$ & -1.98 & 2.47 \\
$\mathrm{E}$ & -0.95 & 17.85 & -1.69 \\
$\mathrm{~F}$ & $-3.38^{*}$ & 4.63 & 4.08 \\
\hline
\end{tabular}

* Estimate differs from zero by the t-test at $5 \%$ probability.

were the only ones in which ability to tolerate was equal to that of exercising competition. Clone A exercised the least competition regardless of the location and spacing. In other words, the other clones when in the vicinity of A showed the greatest mean values. In contrast, clones $\mathrm{E}$ and $\mathrm{F}$ were those which expressed most exercised competition.

The treatment source of variation was broken down into general ability to exercise competition (GEC), general ability to tolerate competition (GTC), and specific competitive ability (SCA). As can be seen, all of these sources of variation were significant $(P \leq 0.05)$. All the interactions involving GEC, GTC, and SCA within locations and spacings were significant $(P \leq 0.05)$ (Table 1$)$. This indicates that the behavior of the clones in toleration or exercising competition did not coincide in the different locations or in the two spacings.

This fact was reflected in the estimates of the parameters of model 4, i.e.; the ability to exercise competition $\left(c_{i}\right)$, per se effect (aj), and toleration of competition ( $\left.t_{j}\right)$, varied a great deal among the environments (Tables 4 and 5). The estimates of the Spearman classifying correlation presented in Table 6 reinforce the previous observation. Notice that in almost all cases, the correlation estimates were of low magnitude or even negative. The lack of coincidence in the estimates of the parameters was expected up to a certain point due to the differences in locations and, above all, of the spacings. Furthermore, the estimates of these parameters are of small magnitude and any fluctuation alters the classification. Considering the most important aspect is to verify
Table 8. - Parameters of specific competitive ability for volume in the mean value of the spacings and locations (Model 4), at 36 months of age.

\begin{tabular}{|c|c|c|c|c|c|c|c|c|}
\hline $\mathrm{i}$ & $\mathrm{j}$ & $s_{i j}$ & i & $\mathrm{j}$ & $\mathrm{s}_{\mathrm{ij}}$ & $\mathrm{i}$ & $\mathrm{j}$ & $\mathrm{s}_{\mathrm{ij}}$ \\
\hline A & A & -0.16 & C & A & 0.95 & $\mathrm{E}$ & A & $5.33 *$ \\
\hline A & B & -0.34 & $\mathrm{C}$ & B & -0.75 & $\mathrm{E}$ & B & 2.91 \\
\hline A & C & -2.41 & C & $\mathrm{C}$ & -1.39 & E & C & -1.76 \\
\hline A & D & $5.52^{*}$ & $\mathrm{C}$ & D & 0.93 & E & D & -3.85 \\
\hline A & $\mathrm{E}$ & $-4.46^{*}$ & $\mathrm{C}$ & $\mathrm{E}$ & 2.59 & E & E & 2.19 \\
\hline A & F & 1.86 & $\mathrm{C}$ & F & -2.33 & E & $\mathrm{F}$ & $-4.83^{*}$ \\
\hline B & A & $-4.42 *$ & D & A & 0.98 & $\mathrm{~F}$ & A & -2.67 \\
\hline B & B & -2.15 & D & B & 1.01 & $\mathrm{~F}$ & B & -0.68 \\
\hline B & $\mathrm{C}$ & 2.35 & D & $\mathrm{C}$ & -0.12 & $\mathrm{~F}$ & $\mathrm{C}$ & 3.33 \\
\hline B & D & -3.02 & D & D & 0.02 & $\mathrm{~F}$ & D & 0.41 \\
\hline B & E & 3.17 & D & $\mathrm{E}$ & -4.25 & $\mathrm{~F}$ & E & 0.75 \\
\hline B & $\mathrm{F}$ & 4.07 & D & $\mathrm{F}$ & 2.36 & $\mathrm{~F}$ & $\mathrm{~F}$ & -1.14 \\
\hline
\end{tabular}

* Estimate differs from 0 by the t-test at $5 \%$ probability.

whether or not there is an advantage in mixing the clones of different management conditions, emphasis will be directed towards the data which is obtained from the mean value of the environments in spite of the interaction detected.

Estimates of the parameters in model 4, regardless of the locations and spacings (Table 7), were as expected; consistent with those reported previously for the clones' ability to exercise competition. The estimate of $c_{i}$, for example, was greater for clone $\mathrm{A}$. Clone $\mathrm{F}$ exhibited a lower estimate of $c_{i}$, i.e., it exercised the greatest competition. The $\mathrm{a}_{\mathrm{i}}$, for its part, evaluates the deviation of performance per se of the clone. Clone A exhibited the lowest performance per se and clone $\mathrm{E}$ exhibited the greatest. The estimate of $t_{j}$ is a very useful parameter because it evaluates the ability to tolerate competition. Clone A exhibited the lowest estimate of $t_{j}$, i.e., the least tolerance, whereas clone $\mathrm{F}$ tolerated the most competition. Unfortunately, the estimates of $c_{i}$ and $t_{j}$ act in opposite directions. In other words, among the six clones evaluated, not one of them has low ability to exercise competition while at the same time high ability to tolerate competition.

A high positive estimate of specific competitive ability $\left(\mathrm{s}_{\mathrm{ij}}\right)$ indicates a good combination if associated with a high mean value of wood volume between the two clones involved. The pair AD (5.52) and EA (5.33) were the only clones which exhibited good estimates of $\mathrm{s}_{\mathrm{ij}}$. In general, the estimates of sij were of low magnitude and statistically equal to zero by the t-test at $5 \%$ (Table 8 ).

\section{Discussion}

The study of competition among a determined group of eucalyptus clones becomes more interesting when clones with different traits are included; however, they were previously tested and approved, thus providing results with practical potential and which are more applicable in the clonal management and silviculture routine. In this study, commercial clones belonging to the same enterprise are included which have recognized high performances. 
Another important aspect which should be emphasized when working with perennial plants is the time period of evaluation in the experiments. As the age within the population increases, the competition for resources such as water, nutrients, and light becomes stronger. However, early selection has been practiced in forestry companies and its efficiency has been shown through diverse literature studies both for selection in forestry genetic breeding (BORRALHO et al., 1992, REZEnde et al., 1994, PEREIRA et al., 1997, Tolfo et al., 2005 e MASSARO et al., 2010), as well as for the volumetric prognosis (ABREU et al., 2002). Thus, it is expected that the estimated competitive parameters at the age of 36 months will be good predictors of behavior at the age of rotation.

The behavior of the clones in autocompetition and allocompetition was not very different, both with very similar mean values being obtained. To begin with, the different locations and spacings did not result in change in mean behavior of the clones in regards to their performance in auto and allocompetition. However, observing the individual behavior of each clone, it is possible to identify situations where the performance in allocompetition is greater. Clone D always presented a greater mean value in allocompetition. Clone $\mathrm{F}$, with the exception of Lagoa do Capim, also presented greater performance in allocompetition. Clone A presented the greatest difference among the magnitude of the mean values, but it was not possible to identify a pattern that associates its behavior in auto and allocompetiton. It is fitting to emphasize that the differences found are of small magnitude. They allow the conclusion that the behavior of the high performing clones, such as clones D, E, and F, were not altered much by auto- or allocompetition. This suggests that the mixture of elite clones does not lead to neither greater increases, nor losses. Clone A, for its part, which has the worst performance per se, with the lowest mean values, stands out as the least competitive and suffered more with the pattern of allocompetition (Table 2).

In the study of effects on the patterns of auto and allocompetition, some strategies may be used. One of them, greatly used in diverse species, is the mixture into equal proportions of lines and/or cultivars one desires to evaluate in regards to relative performance in monoculture and mixed growing (HELland; Holland, 2001). Another option is estimating the parameters of auto-/allocompetition by individuals, as was carried out in this study. This may be performed in a nine-hole system in which the central hole is the individual under competition and in the eight remaining holes is the clone that exercises competition. Thus, estimates may be obtained and each clone may be evaluated by three parameters: ability to exercise competition $\left(\mathrm{c}_{\mathrm{i}}\right)$ when the clone in question is the one which surrounds all the others in the nine-hole system; ability to tolerate competition $\left(t_{j}\right)$ obtained by the clone under competition in the center of the nine holes, eliminating the effect per se $\left(\mathrm{a}_{\mathrm{j}}\right)$ of the clone in question; and by its performance per se $\left(\mathrm{a}_{\mathrm{j}}\right)$ (FEDERER et al., 1982).

The ideal clone for use in a mixture is the one which associates low ability to exercise competition with high tolerance to competition. The greater the value of $c_{i}$, the less it exercises competition, and the greater the value of $t_{j}$, the greater the tolerance. It was found that no one clone, in regards to the mean value of the locations and spacings, possessed the two desirable traits. In general, the clones which exercised little competition were the least tolerant. Clone A is the least competitive (greater $\mathrm{c}_{\mathrm{i}}$ ), tolerates the least competition (lowest $\mathrm{t}_{\mathrm{j}}$ ), and has the worst performance per se. Clones D and $\mathrm{F}$ are the most tolerant, however they are strong competitors. Clone E exhibited the best performance per se and its ability to exercise competition is equal to zero by the ttest at $5 \%$ (Table 7).

The $c_{i}$ of the clones varied a great deal in the different locations and spacings. In general, the effect of the interactions changed the behavior of the estimates of the parameters in the model, as shown by the low correlations among the performance of the clones in the different environments (Table 6).

In principle, the mixture of clones would not be an advantage in regards to wood production. However, upon more careful analysis of the potential benefits of using a mixture of clones, some points should be highlighted. There are reports in other crops (HELLAND; HoLLAND, 2001; MASTRANTONIO et al., 2004; BisoGnin et al., 1995; BRUZI et al., 2007; BotELHO et al., 2011) taking for example the work of BotelHo et al. (2011), on the bean. The two susceptible lines showed $67 \%$ less productivity per land unit than that of a mixture involving eight lines. Brazilian forestry companies had recently failed with recommended clones. If a clonal mix had been recommended, there would have been a smaller total loss than what occurred. The failure of a specific clone could be compensated by different clones in the mix, as in the case of annuals plants.

The mixture of cultivars and/or lines provides greater stability in production. Therefore, with the choice of clones that will compose the mixture, there may be optimization of available resources, such that if one clone does not respond to an environmental change, another may make up for it.

Another potential advantage is in regards to pest and disease management. Some studies report that the use of multilines for greater pest and disease control, contributes to a lower incidence of pathogens and pests than use of a pure line (MILLE; JOUAN, 1997; HELLAND; Holland, 2001; BotelHo et al., 2011). In forest plantations, the use of a mixture of clones could be a component of integrated pest and disease management; such that a block formed of a mixture of clones with different susceptibilities could minimize outbreaks or epidemics.

\section{References}

Abreu, E. C. R., J. R. S. Scolforo, A. D. Oliveira, J. M. Mello and H. Kanegae Júnior (2002): Modelagem para prognose precoce do volume por classe diamétrica para Eucalyptus grandis. Scientia forestalis 61: 86-102.

Bisognin, D. A., F. DE J. Vernetti, M. F. da C. Gastal and E. P. ZoNTA (1995): Competição intergenotípica em soja. Pesquisa Agropecuária Brasileira 30: 947-955. 